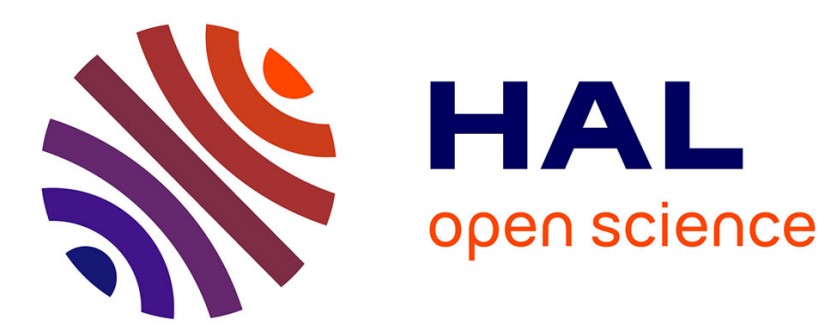

\title{
On the Detonation Wave Propagation
}

\author{
J.-M. Chevalier
}

\section{- To cite this version:}

J.-M. Chevalier. On the Detonation Wave Propagation. Journal de Physique IV Proceedings, 1995, 05 (C4), pp.C4-25-C4-35. 10.1051/jp4:1995402 . jpa-00253701

\section{HAL Id: jpa-00253701 https://hal.science/jpa-00253701}

Submitted on 1 Jan 1995

HAL is a multi-disciplinary open access archive for the deposit and dissemination of scientific research documents, whether they are published or not. The documents may come from teaching and research institutions in France or abroad, or from public or private research centers.
L'archive ouverte pluridisciplinaire HAL, est destinée au dépôt et à la diffusion de documents scientifiques de niveau recherche, publiés ou non, émanant des établissements d'enseignement et de recherche français ou étrangers, des laboratoires publics ou privés. 


\title{
On the Detonation Wave Propagation
}

\author{
J.-M. Chevalier(1) \\ Commissariat à l'Energie Atomique, CEV-M, BP. 7, 77181 Courtry, France
}

A new theoretical approach of the unsteady detonation in condensed explosives was developped. The first experimental results presented in this paper confirm that the evolution of the front can be described by the propagation of front-waves, as predicted by the model. It seems, also, that the speed of these waves is a decreasing function of detonation velocity and doesn't depend on the confinement of the explosive.

\section{INTRODUCTION}

A new model describing the detonation front propagation in condensed explosives (named $\mathrm{Jr}$ model) has been recently proposed by L. Brun [1-2]. First macroscopic model of the unsteady detonation, the Chapman-Jouguet model [3] assumes an instantaneous and complete decomposition across a downstream sonic discontinuity. But the condition of a detonation propagation at constant velocity doesn't agree with the curved steady revolution detonation (SRD) fronts observed on condensed explosives. The Zeldovitch-Von Neuman-Döring model ZND [4-5] assumes that the decomposition goes on behind a non reactive and hence subsonic discontinuity. The ZND model agrees for interpretations of the SRD [6], but appears difficult to extend to unstationnary cases like spherically diverging detonation.

In $\mathrm{Jr}$ model, the front acceleration is related to its curvature by two functions of the local detonation velocity: the characteristic curvature, which has been already studied (Aveillé,Bdzil) [711], and a new function, the characteristic speed, which describes the propagation of front-waves.

Original experiments was performed in order to check the model, in TATB and HMX based compositions, to confirm the front-waves propagation.

\section{THE Jr MODEL}

Three assumptions govern the model. The detonation front is assimilated to an infinitely thin and downstream sonic discontinuity. But this model does not suppose, as Jouguet's did, a total decomposition within the front, and thus accordingly releases Jouguet's condition $D=D_{c j}[1]$. The acceleration of a self-sustained detonation wave front is given by the relation:

$$
\delta \mathrm{D} / \delta \mathrm{t}=2 \mathrm{C}^{2}(\mathrm{D})[\mathrm{K}(\mathrm{D})-\mathscr{C}] \text {, }
$$

where $\mathscr{C}$ is the curvature of the front, $C(D)$ the velocity of the front-waves and $K(D)$ the celeritycurvature relationship. 
The associated boundary condition is:

$$
\mathrm{B}\left(\theta_{\mathrm{b}}, \mathrm{D}_{\mathrm{b}}\right)=\mathrm{O}
$$

where $\theta_{b}$ is the front inclination on the unperturbed interface and $D_{b}$ the front velocity at the boundary. relation:

The characteristic angle connects the front-wave speed with the detonation velocity by the

$$
\operatorname{tg} \varphi=\mathrm{C}(\mathrm{D}) / \mathrm{D}
$$

\section{ASSOCIATED EXPERIMENTS}

The Jr model can easily be used to describe what would happen in a cylindrical geometry: if a steady detonation propagates in an explosive cylinder, a sudden reduction of the diameter generates a circular perturbation which propagates inwards.

As shown figure 1, the model tells that, if the perturbation starts at time $t_{0}$, at $t_{0}+d t$ a length Cdt of the front will be modified. The TT' surface is not yet affected, and is determined by a translation of the NN' surface.

These phenomena must be experimentaly observed in order to check the model.

FIGURE 1 : DISPLAY PRINCIPLE OF FRONT WAVES

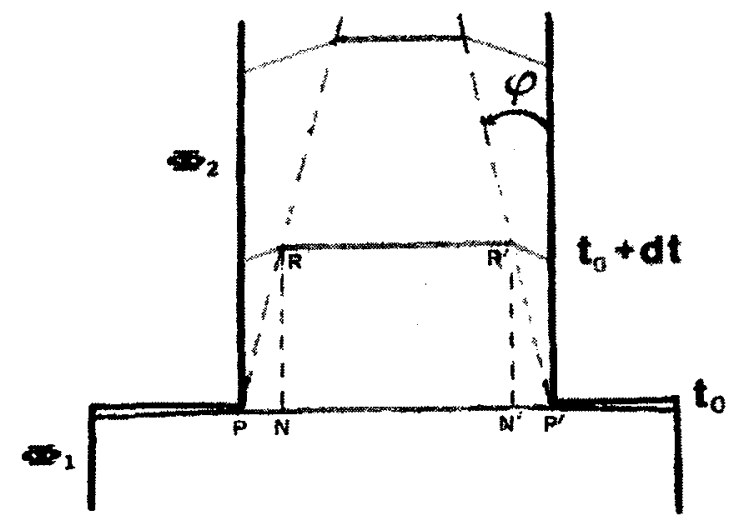

\section{EXPERIMENTAL SET-UP}

The experimental set-up used to observe the detonation front and to measure the front-wave speed is presented figure 2 .

A plane wave generator initiates a detonation wave in an unconfined explosive cylinder (diameter $\phi_{1}$ ). Its length $\mathrm{H}_{1}$ is chosen in order to achieve a steady detonation. The cylinder free surface is metallized for the optical recording of the front motion.

An argon flash-light is reflected by the surface and focused on a streak camera. When the 
detonation wave interacts with the surface, the damage of the metal spray is recorded on the film.

In another experiment a cylinder of diameter $\phi_{2}\left(\phi_{2}<\phi_{1}\right)$ and length $\mathrm{H}_{2}$ is added to the previous one, and the detonation front is observed by using the same technics. Comparison of the shapes of the waves which emerge from both cylinders yields the velocity of the front-waves.

FIGURE 2 - DISPLAY EXPERIMENTAL SET-UP OF FRONT WAVES IN EXPLOSIF.

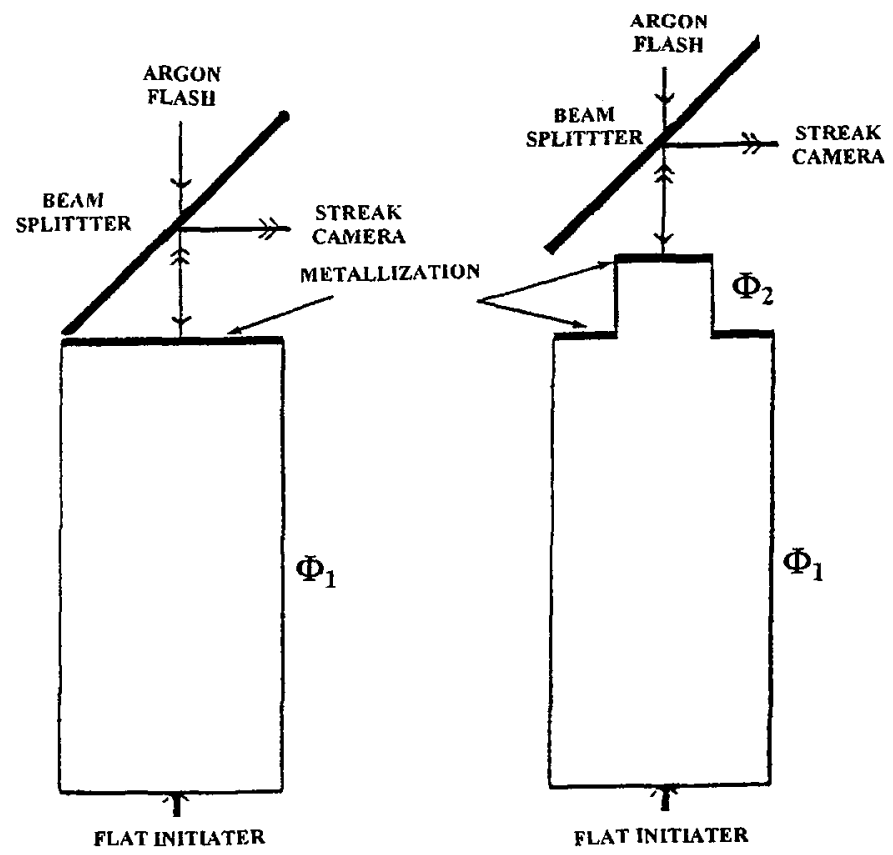

\section{EXPERIMENTAL RESULTS}

\section{TATB BASED COMPOSITION T2 (97\% TATB)}

In order to study the variation of the front-waves speed $C$ versus the detonation velocity $D$, several cylinder diameters $\phi_{1}$ have been tested. For $T_{2}$ composition, as for others TATB compositions, the detonation velocity is strongly dependent on the cylinder diameter ( Aveillé ) [10$11]$.

Figure 3 presents the optical records obtained in one configuration. In the first experiment, the dimensions were $\phi_{1}=30 \mathrm{~mm}, \mathrm{H}_{1}=120 \mathrm{~mm}$. In the second experiment, a cylinder $\phi_{2}=15 \mathrm{~mm}, \mathrm{H}_{2}=15$ $\mathrm{mm}$ is added.

No noise perturbs the records. The superposition of the two measurements gives an accurate determination of the front-waves speed. The central part of the front, delimited by the two points $T$ and $\mathrm{T}^{\prime}$, is not yet affected by the perturbations propagated by the front -waves, as predicted by the $\mathrm{Jr}$ model. 
As defined figure 1, D and $C$ are given by the relation : $D=N T / d t, C=P N / d t . C$ is the average value of the front waves velocity. $D$ is in good agreement with previous measurements [10-11].

The values of $C(D)$, reported in table 1 , show that $C$ is a decreasing function of $D$ [12].

FIGURE 3 - EXTENDING SUPERPOSITION OF $T_{2} \phi_{1}=30$ AND $\phi_{2}=15$ WAVES OUT

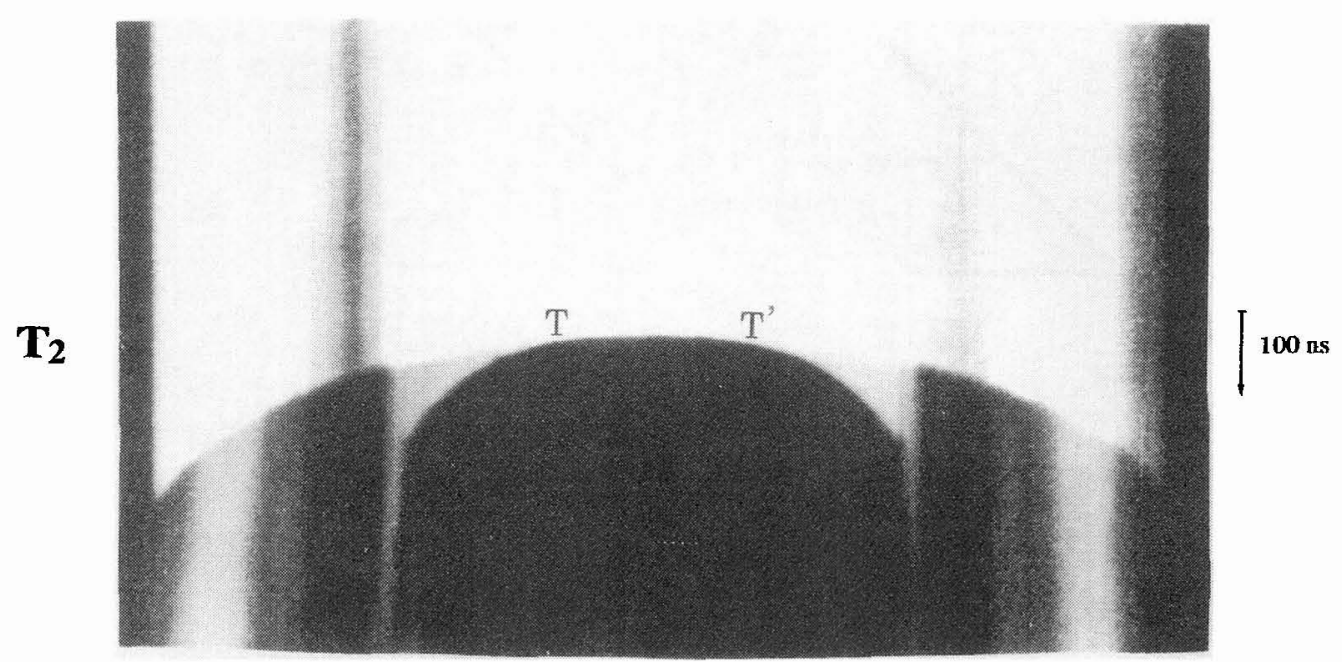

TABLE 1 - MEASURED VALUES ON $T_{2}$ COMPOSITION

\begin{tabular}{||c|c|c|c|c|ccc||}
\hline \begin{tabular}{c}
\hline$\Phi_{1} / \Phi_{2}$ \\
$(\mathrm{~mm})$
\end{tabular} & $\begin{array}{c}\mathrm{H}_{2} \\
(\mathrm{~mm})\end{array}$ & $\begin{array}{c}\mathbf{D} \\
(\mathrm{m} / \mathrm{s})\end{array}$ & $\begin{array}{c}\mathbf{C}(\mathrm{D}) \\
(\mathrm{m} / \mathrm{s})\end{array}$ & $\begin{array}{c}\varphi \\
\left({ }^{\circ}\right)\end{array}$ & $\begin{array}{c}\Delta \mathrm{D} \\
(\mathrm{m} / \mathrm{s})\end{array}$ & $\begin{array}{c}\Delta \mathrm{C} \\
(\mathrm{m} / \mathrm{s})\end{array}$ & $\begin{array}{c}\Delta \varphi \\
\left({ }^{\circ}\right)\end{array}$ \\
\hline \multirow{2}{*}{$30 / 15$} & 15 & $\mathbf{7 5 3 8}$ & $\mathbf{2 8 1 0}$ & $\mathbf{2 0 . 4}$ & 35 & 250 & 2 \\
\cline { 3 - 8 } & & $\mathbf{7 5 1 9}$ & $\mathbf{2 8 1 0}$ & $\mathbf{2 0 . 5}$ & 35 & 250 & 2 \\
\hline $75 / 50$ & 40 & $\mathbf{7 6 2 7}$ & $\mathbf{1 8 8 0}$ & 13.8 & 20 & 140 & 1 \\
\hline $100 / 50$ & 40 & $\mathbf{7 6 0 3}$ & $\mathbf{2 1 7 0}$ & $\mathbf{1 5 . 9}$ & 20 & 140 & 1 \\
\hline
\end{tabular}

To complete the determination of function $C(D)$, a serie of experiments have been realised with cylinder diameters $f_{1}$ decreasing from 75 to $10 \mathrm{~mm}$. In these conditions the detonation velocity decreases from 7630 to $7290 \mathrm{~m} / \mathrm{s}$ [10-11]. The measured values of C(D) are reported on table 2 . The variations of front-waves speed $C$ versus the detonation velocity are recorded on figure 4 . These results confirm that $C$ is decreasing function of $D$. The last value seems to 
express that the front-wave speed increases strongly near the critical diameter $\left(\phi_{c}=8.5 \mathrm{~mm}\right.$ for $\mathrm{T}_{2}$ composition). Neverthless, this value needs to be confirm.

\section{TABLE 2 - STUDY OF THE C(D) FUNCTION ON $T_{2}$ COMPOSITION}

\begin{tabular}{|c|c|c|c|c|c|c|c|c|}
\hline $\begin{array}{l}\Phi_{1} / \Phi_{2} \\
(\mathrm{~mm}) \\
\end{array}$ & $\begin{array}{c}\mathrm{H}_{1} \\
(\mathrm{~mm})\end{array}$ & $\begin{array}{r}\mathrm{H}_{2} \\
(\mathrm{~mm})\end{array}$ & $\underset{(\mathrm{m} / \mathrm{s})}{\mathbf{D}}$ & $\begin{array}{l}C(D) \\
(\mathrm{m} / \mathrm{s})\end{array}$ & $\begin{array}{c}\varphi \\
\left(^{\circ}\right) \\
\end{array}$ & $\begin{array}{c}\Delta \mathrm{D} \\
(\mathrm{m} / \mathrm{s}) \\
\end{array}$ & $\begin{array}{c}\Delta \mathrm{C} \\
(\mathrm{m} / \mathrm{s}) \\
\end{array}$ & $\begin{array}{l}\Delta \varphi \\
\left({ }^{\circ}\right) \\
\end{array}$ \\
\hline $75 / 50$ & 510 & 40 & 7626 & 1990 & 14.6 & 8 & 100 & 0.8 \\
\hline $60 / 40$ & 370 & 30 & 7612 & 1990 & 14.7 & 10 & 130 & 1 \\
\hline $40 / 20$ & 240 & 14 & 7560 & 2320 & 17.1 & 20 & 140 & 1 \\
\hline $30 / 15$ & 160 & 10 & 7558 & 2490 & 18.2 & 30 & 200 & 1.5 \\
\hline $20 / 14$ & 100 & 9 & 7502 & 2670 & 19.6 & 30 & 220 & 2 \\
\hline \multirow{2}{*}{$15 / 10$} & \multirow{2}{*}{75} & 4 & 7438 & 3350 & 24.2 & 70 & 400 & 3 \\
\hline & & 6 & 7413 & 3210 & 23.4 & 45 & 270 & 2 \\
\hline $10 / 6$ & 50 & 2 & 7326 & 5860 & 38.7 & 135 & 840 & 6 \\
\hline
\end{tabular}

In a second study two experiments series have been performed to observe the variation of front-wave speed $\mathrm{C}$ with the time.

In this case, configurations with $\phi_{1}=50 \mathrm{~mm}, \phi_{2} \approx 30 \mathrm{~mm}$ and $\mathrm{H}_{2}=10$ to $50 \mathrm{~mm}$ by $10 \mathrm{~mm}$ step has been tested. For this configuration the detonation velocity on the axis wouldn't vary.

The experimental results are reported on table 3 . The measured values of $C$ confirm that to one detonation velocity value $D$ is associated one front-wave speed $C$, taking the experimental accuracy into consideration.

\section{HMX BASED COMPOSITUNS XI AND X2 $(96$ I:I $94,2 \%$ HMX )}

These two HMX based compositons differ essentially by their binders. The measured values of C(D) [12] are reported in table 4.

In both compositions, the values are nearly the same, as expected, and lower than those found for the TATB composition.

For the experiments on HMX compositions, decrease of the detonation velocity is not significant enough to check whether function $C(D)$ is decreasing or not. 
TABLE 3: MEASURED VALUES OF FRONT-WAVES SPEED VERSUS THE TIME ON $\mathrm{T}_{2}$ COMPOSITION

\begin{tabular}{|c|c|c|c|c|c|c|c|c|}
\hline $\begin{array}{l}\Phi_{1} / \Phi_{2} \\
(\mathrm{~mm})\end{array}$ & $\begin{array}{c}\mathrm{H}_{1} \\
(\mathrm{~mm})\end{array}$ & $\begin{array}{c}\mathrm{H}_{2} \\
(\mathrm{~mm}) \\
\end{array}$ & $\begin{array}{c}\text { D } \\
(\mathrm{m} / \mathrm{s})\end{array}$ & $\begin{array}{l}C(D) \\
(\mathrm{m} / \mathrm{s})\end{array}$ & $\begin{array}{c}\varphi \\
\left({ }^{\circ}\right) \\
\end{array}$ & $\underset{(\mathrm{m} / \mathrm{s})}{\Delta \mathrm{D}}$ & $\begin{array}{c}\Delta \mathrm{C} \\
(\mathrm{m} / \mathrm{s})\end{array}$ & $\begin{array}{l}\Delta \varphi \\
\left({ }^{\circ}\right) \\
\end{array}$ \\
\hline \multirow{5}{*}{$50 / 30$} & \multirow{5}{*}{300} & 10 & 7612 & 2090 & 15.4 & 30 & 390 & 3 \\
\hline & & 20 & 7607 & 2020 & 14.9 & 15 & 195 & 1.5 \\
\hline & & 30 & 7607 & 1990 & 14.7 & 10 & 130 & 1 \\
\hline & & 40 & 7606 & 2170 & 15.9 & 8 & 65 & 0.5 \\
\hline & & 50 & 7609 & 2025 & 14.9 & 6 & 40 & 0.5 \\
\hline
\end{tabular}

Figure 4 - Variation of front-waves speed $C$ versus the detonation velocity

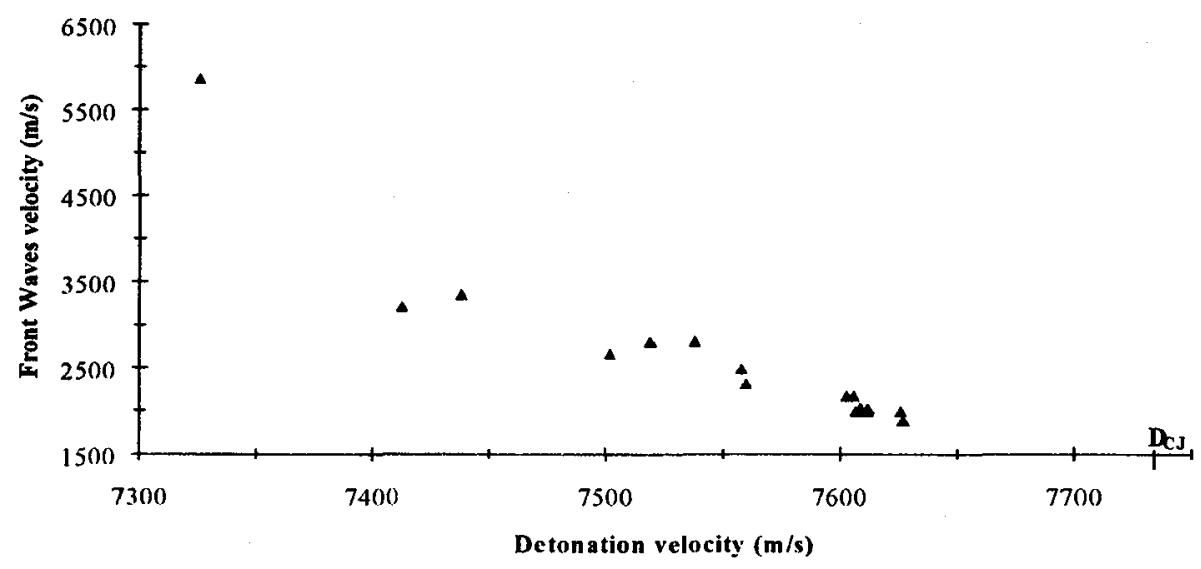

TABLE 4 - MEASURED VALUE ON $x_{1}$ AND $x_{2}$ COMPOSITION

\begin{tabular}{|c|c|c|c|c|c|ccc|}
\hline Composition & $\begin{array}{c}\Phi_{1} / \Phi_{2} \\
(\mathrm{~mm})\end{array}$ & $\begin{array}{c}\mathrm{H}_{2} \\
(\mathrm{~mm})\end{array}$ & $\begin{array}{c}\mathbf{D} \\
(\mathrm{m} / \mathrm{s})\end{array}$ & $\begin{array}{c}\mathbf{C}(\mathbf{D}) \\
(\mathrm{m} / \mathrm{s})\end{array}$ & $\begin{array}{c}\varphi \\
\left({ }^{\circ}\right)\end{array}$ & $\begin{array}{c}\Delta \mathrm{D} / \mathrm{s}) \\
(\mathrm{m} / \mathrm{s})\end{array}$ & $\begin{array}{c}\Delta \varphi \\
\left({ }^{\circ}\right)\end{array}$ \\
\hline \hline $\mathrm{X}_{1}$ & $25 / 10$ & 20 & 8755 & 1450 & 9.4 & 40 & 100 & 1 \\
\hline $\mathrm{X}_{1}$ & $50 / 30$ & 30 & 8744 & 1530 & 9.9 & 25 & 100 & 1 \\
\hline$X_{2}$ & $100 / 50$ & 40 & 8767 & 1420 & 9.2 & 20 & 100 & 1 \\
\hline$X_{2}$ & $100 / 50$ & 80 & 8760 & 1320 & 8.5 & 10 & 100 & 1 \\
\hline
\end{tabular}




\section{INTIUUFNCE OF TIIE CONFINI:MENT}

The $\mathrm{Jr}$ model predicts that $\mathrm{C}$ is a function of the detonation velocity and will not depend on the boundary conditions. Some experiments were performed with an aluminum case around the second explosive cylinder. The results are given in table 5 .

TABLE 5 - INFLUENCE OF THE CONFINEMENT COMPOSITION

\begin{tabular}{|c|c|c|c|c|c|c|c|c|}
\hline Confinement & $\begin{array}{l}\Phi_{1} / \Phi_{2} \\
(\mathrm{~mm}) \\
\end{array}$ & $\begin{array}{r}\mathrm{H}_{2} \\
(\mathrm{~mm}) \\
\end{array}$ & $\begin{array}{c}\mathbf{D} \\
(\mathrm{m} / \mathrm{s}) \\
\end{array}$ & $\begin{array}{l}\mathbf{C}(\mathbf{D}) \\
(\mathrm{m} / \mathrm{s})\end{array}$ & $\begin{array}{c}\varphi \\
(\rho) \\
\end{array}$ & $\begin{array}{c}\Delta D \\
(\mathrm{~m} / \mathrm{s}) \\
\end{array}$ & $\begin{array}{c}\Delta \mathrm{C} \\
(\mathrm{m} / \mathrm{s}) \\
\end{array}$ & $\begin{array}{l}\Delta \varphi \\
\left({ }^{\circ}\right) \\
\end{array}$ \\
\hline Air & \multirow{2}{*}{$100 / 50$} & \multirow{2}{*}{40} & 8767 & 1420 & 9.2 & 20 & 100 & 1 \\
\hline 2024 & & & 8787 & 1370 & 8.9 & 20 & 100 & 1 \\
\hline Air & \multirow{3}{*}{$100 / 50$} & \multirow{3}{*}{40} & 7603 & 2170 & 15.9 & 20 & 140 & 1 \\
\hline Steel & & & 7646 & 2060 & 15.1 & 20 & 140 & 1 \\
\hline 2024 & & & 7651 & 1940 & 14.2 & 20 & 140 & 1 \\
\hline
\end{tabular}

The measured values of $\mathrm{C}$, with and without confinement, are very close to each other. Of course, the shapes of the detonation fronts are very different : the front-waves move with the same speed, but they do not carry the same information.

\section{UNSTEADY REGIME}

In the experiment depicted on figure 5 the detonation was initiated in a cylinder of $T_{2}$ composition by a plane detonation making an angle of $74^{\circ}$ with the axis. It appears that the detonation in the $T_{2}$ cylinder evolves towards the stationnary shape which would be observed when initiation is perpendicular to the axis.

Indeed several configurations have been performed with $\mathrm{T}_{2}$ cylinders which dimensions are respectively $\phi=50 \mathrm{~mm}$ and $\mathrm{H}=100,200,400$ and $600 \mathrm{~mm}$. For the first, the optical record presented (figure 6) shows an assymetrical detonation front with regard to the axis. For the third, the detonation front (figure 7) was setted partly, presenting a weak assymetry.

For this configuration, the perturbation due to the diameter reduction and which propagates inwards, is arrived at cylinder center and is came back two times before the detonation emergence. For the last, the recorded detonation front was setted and presents the same characteristics as a detonation front with a perpendicular to the axis initiation. 
Figure 5 - Experiences in unsteady detonation field

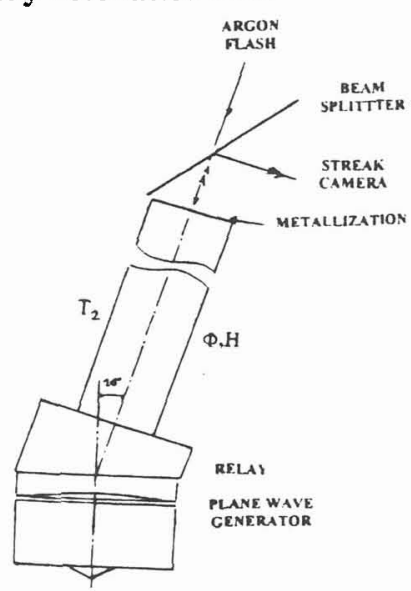

FIGURE 6 - Optical record of detonation in $T_{2}$ cylinder $(\phi=50 \mathrm{~mm}$ et $\mathrm{H}=100 \mathrm{~mm})$ initiated by a plane detonation making an angle of $74^{\circ}$ with the axis
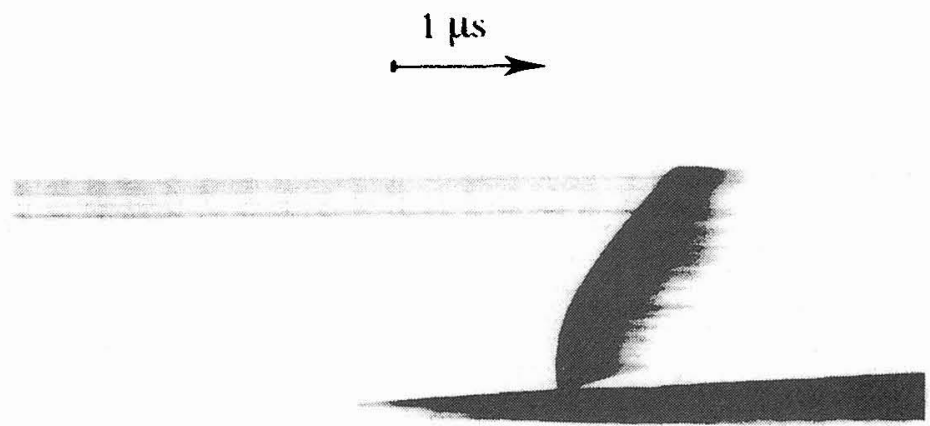

FIGURE 7 - Optical record of detonation in $T_{2}$ cylinder $(\phi=50 \mathrm{~mm}$ et $\mathrm{H}=400 \mathrm{~mm})$ initiated by a plane detonation making an angle of $74^{\circ}$ with the axis

$1 \mu s$ 
FIGURE 8 - Experimental set-up of the zero method for boundary condition determination

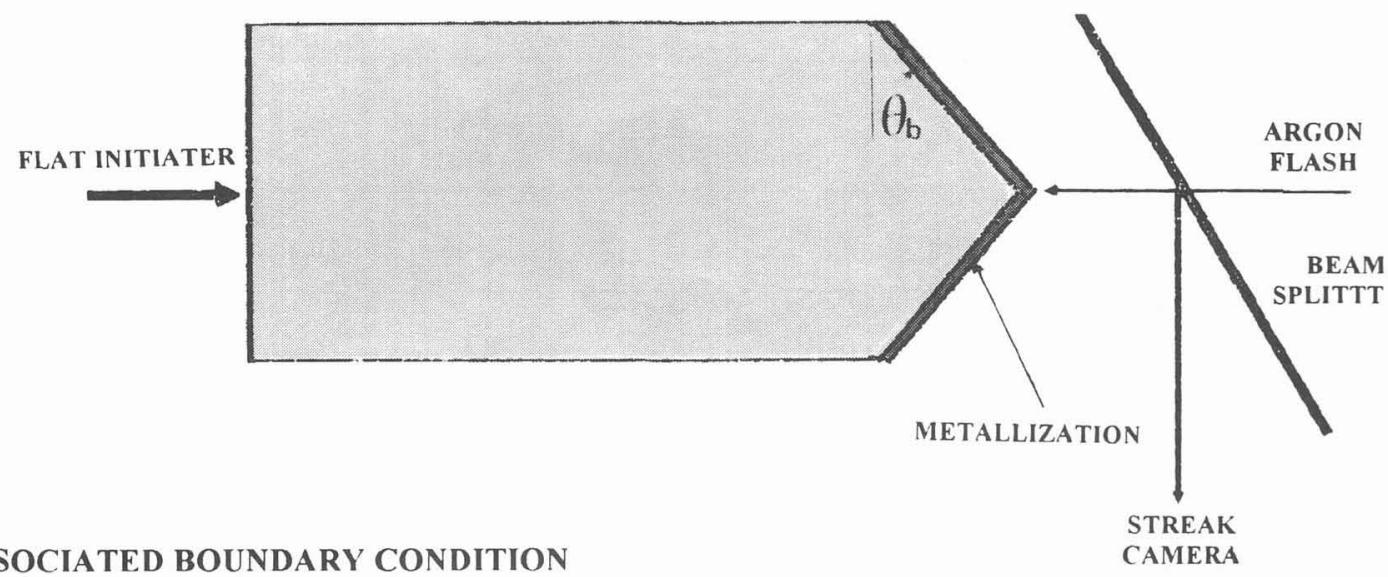

For this study, two methods were used to measure the front inclination. The first (classical method) is based on the front detonation record at the end of explosive cylinder. For the second (zero method), this cylinder is terminated in cone ("pencil") with an inclination $\mathrm{q}_{\mathrm{b}}$ corresponding to the presumed value. This method allows a more accurate measure of the motion at this presumed value. The experimental set-up of this method and the optical record obtained for $\mathrm{T}_{2}$ cylinder with $30 \mathrm{~mm}$ diameter are presented respectively figures 8 and 9 . Measures were obtained after digitalization and linear approximation on $0.7 \mathrm{~mm}$ of boundary front wave. The measured values for $T_{2}$ composition are showed on table 6 . The boundary detonation velocity is given by the relation $D_{b}=D$. cosq $q_{b}$, where the $D$ values were measured by Aveillé and Col. [10-11]. The classical method, though less accurate, is given interesting results.

FIGURE 9 - Optical record for T2 "pencil" ( $\phi=30 \mathrm{~mm}$ et $\mathrm{H}=180 \mathrm{~mm}$ )

$100 \mathrm{~ns}$

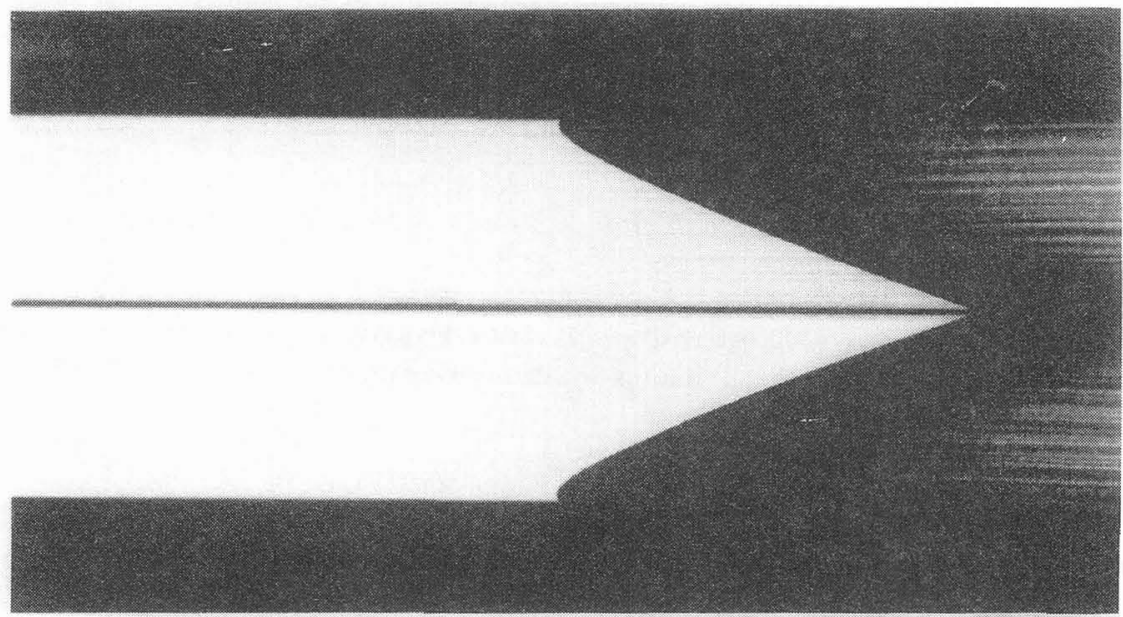


TABLe 6 - Measured values OF THE boundaRy CONDITION ON $\mathbf{T}_{2}$ COMPOSITION.

\begin{tabular}{|c|c|c|c|c|}
\hline & \multicolumn{3}{|c|}{ (Zéro method)) } & (Classical meth \\
\hline $\begin{array}{c}\Phi \\
(\mathrm{mm}) \\
\end{array}$ & $\begin{array}{c}D_{b} \\
(m / s)\end{array}$ & $\begin{array}{c}\Theta_{h} \\
\left(^{\circ}\right) \\
\end{array}$ & $\begin{array}{c}\mathrm{Db}_{\mathrm{b}} \\
(\mathrm{m} / \mathrm{s})\end{array}$ & $\begin{array}{l}\Theta b \\
\rho^{\circ}\end{array}$ \\
\hline 50 & & & 7145 & 20.1 \\
\hline 40 & & & 7095 & 20.2 \\
\hline 30 & 7095 & 19.8 & 7110 & 19.8 \\
\hline 20 & 7020 & 20.7 & 7065 & 19.6 \\
\hline 15 & 6885 & 22.7 & 6925 & 21.1 \\
\hline 10 & & & 6450 & 28.3 \\
\hline 9 & & & 6340 & 29.6 \\
\hline
\end{tabular}

\section{CONCLUSION}

$$
\Delta^{\Theta}{ }_{b^{\sim}}^{\circ}
$$

The experimental results presented in this paper are in general agreement with the front wave propagation phenomena as described by the Jr model. They were obtained for TATB or HMX based compositions, which exhibit very different front curvatures and these preliminary results seem to confirm the basic assumption of a front-wave speed that only depends upon the detonation velocity.

The results on TATB based composition show that $C$ is a decreasing function of $D$. Experiments performed on HMX based compositions can't lead to same conclusions. Results on TATB (C(D) function associated with the boundary condition values) would certainly allow to treat more physically the detonation in calculations.

\section{REFERENCES}

[1] L. Brun "Une théorie de la détonation dans les explosif condensés fondée sur l'hypothèse de Jouguet" CEA Report (Unpublished 1989)

[2] L. Brun "Un nowveau modèle macroscopique de la détonation non soutemıe dans les explosifs condensés" Symposium International Hautes Pressions Dynamiques, la Grande Motte p.103-107, CEA eds (1989)

[3] E. Jouguet "Mécanique des explosifs" Doin et fils eds (1917)

[4] R. Courant and K.O. Friedrichs "Supersonic flow and shock woves" I.P. (1948) 
[5] W. Fickett and D.C. Davis "Detonation" University of California Press (1979)

[6] J.B. Bdzil "Steady-statetwo-dimensional detonation" J. Fluid. Mech., 108, 195-226 (1981)

[7] J.B. Bdzil and D.S. Stewart "Modeling two dimensionnal detonations with detonation shock dynamics" Phys. of fluid, 1,7, P. 1261-67 (1989)

[8] C. Bianchi, N. Carion and J. Aveille CEA Report (Unpublished 1987)

[9] C. Perennes, C. Bianchi, N. Carion and F.Chaissé CEA Report (Unpublished 1988)

[10] J. Aveillé, J. Baconin, N. Carionand J. Zoé "Experimental study of spherically diverging detonation waves" The Eighth Symposium International on Detonation, 523-527, Albuquerque (1985)

[11] F. Chaissé, J.M. Servas, J. Aveillé, J. Baconin, N. Carion and P. Bongrain "A theoretical analysis of the shape of a steady axisymmetrical reactive shock front in cylindrical charges of high explosive. A curvature-diameter relationship" The Eighth Symposium International on Detonation, 539-547, Albuquerque (1985)

[12] J-M. Chevalier, N. Carion, J-C. Protat et J-C. Redasse " Propagation phenomena on the detonation wave front" Physical Review Letters Vol. 71-5, 710-714 (1993) 